\title{
A New Class of Ubiquitin Extension Proteins Secreted by the Dorsal Pharyngeal Gland in Plant Parasitic Cyst Nematodes
}

\author{
Tom Tytgat, ${ }^{1}$ Bartel Vanholme, ${ }^{2}$ Jan De Meutter, ${ }^{3}$ Myriam Claeys, ${ }^{1}$ Marjolein Couvreur, ${ }^{1}$ \\ Isabelle Vanhoutte, ${ }^{3}$ Greetje Gheysen, ${ }^{2}$ Wim Van Criekinge, ${ }^{2}$ Gaetan Borgonie, ${ }^{1}$ August Coomans, ${ }^{1}$ \\ and Godelieve Gheysen ${ }^{2}$
}

${ }^{1}$ Department of Biology, Section Nematology, Ghent University, K.L. Ledeganckstraat 35, B-9000 Gent, Belgium; ${ }^{2}$ Department of Molecular Biotechnology, Faculty of Agricultural and Applied Biological Sciences, Ghent University, Coupure links 653, B-9000 Gent, Belgium; ${ }^{3}$ Flanders Interuniversity Institute for Biotechnology, Department of Plant Systems Biology, Ghent University, K.L. Ledeganckstraat 35, B-9000 Gent, Belgium

Submitted 20 October 2003. Accepted 6 March 2004.

By performing cDNA AFLP on pre- and early parasitic juveniles, we identified genes encoding a novel type of ubiquitin extension proteins secreted by the dorsal pharyngeal gland in the cyst nematode Heterodera schachtii. The proteins consist of three domains, a signal peptide for secretion, a mono-ubiquitin domain, and a short $\mathrm{C}$-terminal positively charged domain. A gfp-fusion of this protein is targeted to the nucleolus in tobacco BY-2 cells. We hypothesize that the C-terminal peptide might have a regulatory function during syncytium formation in plant roots.

Additional keyword: Globodera

Plant parasitic nematodes are a major pest of many crop species. They form a very diverse group, of which the sedentary root endoparasites, comprising the cyst and root-knot nematodes, are the most evolved and interact intricately with their host (Tytgat et al. 2000). Upon infection, the second-stage juveniles of cyst nematodes penetrate into the root tissue and migrate toward the vascular cylinder, where they induce a syncytium by injecting pharyngeal gland secretions into a selected initial feeding cell (Davis et al. 2000). In response to the nematode stimulus, the initial feeding cell rapidly enlarges, the central vacuole disintegrates into several small vacuoles, and organelles, such as the endoplasmic reticulum, ribosomes, mitochondria, and dictyosomes, rapidly proliferate (Fenoll et al. 1997). In the process of syncytium formation, neighboring cells react in a similar way, and partial cell wall dissolution between these cells occurs a few hours later, followed by fusion of the protoplasts. When the feeding cell further enlarges, the normal vascular structure is destroyed, resulting in a severely disturbed solute transport. Feeding site formation involves drastic changes

T. Tytgat and B. Vanholme contributed equally to this work.

Corresponding author: G. Gheysen. E-mail: Godelieve.Gheysen@UGent.be

Current address of T. Tytgat: Department of Pharmacology, Robert Wood Johnson Medical School, University of Medicine and Dentistry of New Jersey, 675 Hoes Lane, Piscataway, NJ, 08854, U.S.A.

Current address of J. De Meutter and Greetje Gheysen, CropDesign N.V., Technologiepark 3, B-9052 Gent, Belgium.

The DNA sequence data reported are available in the NCBI database under accessions numbers AY286305 (Hs-Ubil) and AY288520 (Hs-Ubi2). in gene expression in these root cells, of which activation of cell cycle genes followed by DNA endoreduplication is the most striking (Gheysen and Fenoll 2002). The feeding site serves as nutrient source for the developing nematode, which alternates cycles of cytoplasm withdrawal and injection of pharyngeal gland secretions, both by means of a hollow protrusible stylet (Wyss and Zunke 1986).

The cause of the formation of the feeding cells and the reactivation of the cell cycle is still unknown. Three pharyngeal glands are recognized, two subventral and one dorsal. In preparasitic juveniles, the two subventral glands are very active, but their activity and size drastically decrease during root penetration and migration prior to feeding cell induction (Tytgat et al. 2002; Wyss 1992). In contrast, the dorsal pharyngeal gland increases enormously at the onset of the parasitic life stages. To be able to understand the complex nematode-plant interaction, characterization of these secretions is a necessity. Until now, several genes encoding pharyngeal gland secretions have been identified (Davis et al. 2000; Gao et al. 2003). However, most of those with a known function are subventral gland-specific and are involved in weakening of the cell wall during intracellular migration of the juvenile in the root tissue (De Meutter et al. 2001; Smant et al. 1998).

Based on observations that the pharyngeal gland secretions are differentially expressed during juvenile development (Davis et al. 1994; Tytgat et al. 2002), we assumed that it should be possible to identify the genes encoding these secretions by mRNA fingerprinting on preparasitic and parasitic second-stage juveniles (J2). Therefore, we analyzed mRNA expression by means of cDNA amplification fragment length polymorphism (AFLP) (Bachem et al. 1996) on pre- and early parasitic stages in Heterodera schachtii. Transcripts that were differentially expressed during these early stages were isolated and sequenced. Two of those encoded a new class of ubiquitin extension proteins that are specifically produced in and secreted by the dorsal pharyngeal gland.

\section{RESULTS}

\section{Identification of differentially expressed transcripts by cDNA AFLP.}

Twenty $H$. schachtii juveniles were collected at three developmental stages, preparasitic J2, and parasitic J2 two (moment 
of syncytium induction) and four (feeding and maintenance of the syncytium) days after root inoculation. As the pharyngeal glands are only present in the anterior ends of the nematode, the juveniles were cut midway, so that the mRNA fingerprint of the posterior nematode ends could serve as a negative control. Because the pseudocoel of nematodes is under high hydrostatic pressure, perforation of the nematode's body is coupled with the extrusion of the organs. Therefore, prior to microdissection, the juveniles were partially dehydrated in hypertonic buffer. The intactness of the pharyngeal glands after cutting was verified by transmission electron microscopy (data not shown). Also, incubation for up to two hours in the hypertonic buffer did not lead to mortality, as J2 that were transferred back to water regained their mobility after a few minutes. Total RNA was isolated separately from the anterior and posterior ends, and cDNA of all different samples was synthesized simultaneously. The cDNA was amplified to obtain sufficient material. Thereafter, the cDNA was digested with SacI and $M s e I$ restriction enzymes, the respective adaptors were ligated and the obtained fragments were subjected to the AFLP procedure. Transcript derived fragments (TDF) specific for the anterior ends of the juveniles and showing a differential expression during the onset of parasitism were isolated, cloned, and sequenced. Two TDF, AFT70 and AFT88, were highly similar (97\% identity) and showed significant homology to polyubiquitin from plants. AFT88 was moderately expressed in the preparasitic $\mathrm{J} 2$, highly expressed in the parasitic $\mathrm{J} 2$ two

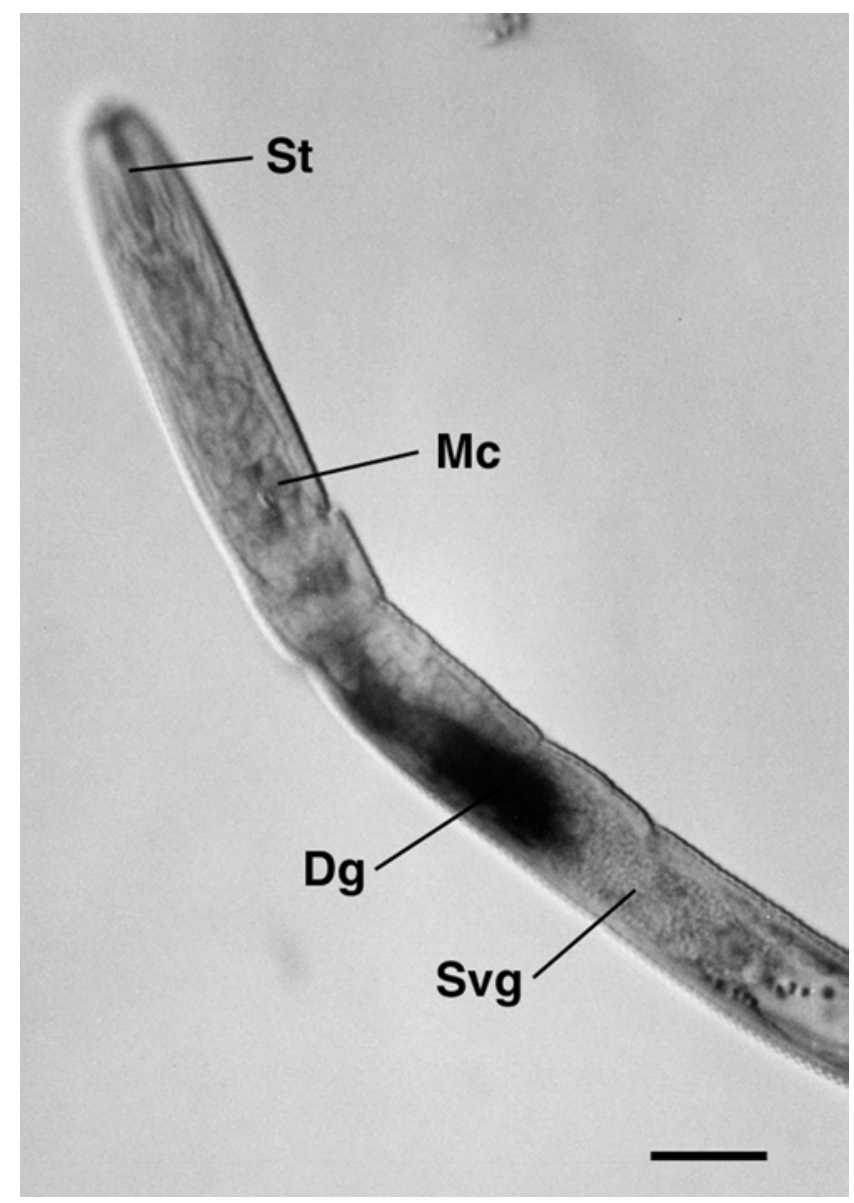

Fig. 1. Whole-mount in situ hybridization. Preparasitic juveniles of Heterodera schachtii were hybridized with a digoxigenin-labeled antisense probe of AFT88. A clear staining is specifically observed in the dorsal pharyngeal gland $(\mathrm{Dg}) . \mathrm{St}=$ Stylet, $\mathrm{Svg}=$ subventral pharyngeal gland, and $\mathrm{Mc}=$ metacorpus. Scale bar $=25 \mu \mathrm{m}$. days after inoculation, and weakly expressed in the parasitic $\mathrm{J} 2$ four days after inoculation. In contrast, AFT70 was highly expressed in the preparasitic and the parasitic $\mathrm{J} 2$ four days after inoculation and moderately expressed in the parasitic $\mathrm{J} 2$ two days after inoculation.

\section{Full-length cDNA analysis of AFT88.}

As both TDF comprised the $3^{\prime}$ end of the open reading frame, two sequence-specific reverse primers of AFT88 were designed. By nested PCR with these primers and a vector primer, the $5^{\prime}$ end of the open reading frame was amplified from a plasmid cDNA library. The amplification product was cloned in pGEMT, and several clones were tested for their insert size. The clones with the largest insert were sequenced. A consensus sequence was made of the different obtained sequences, and based on the overlap with AFT88, the full-length cDNA coding sequence was generated in silico and called $\mathrm{Hs}_{\mathrm{s}}$ Ubil. The 366-bp open reading frame coded for a 122-amino acid protein having three different domains. The first 24 amino acids were predicted with the Signal $\mathrm{P}$ program to encode a signal peptide for secretion. The second domain, containing 76 amino acids, showed $96 \%$ similarity to the ubiquitin domain in polyubiquitin of Pinus sylvestris. The third domain at the Cterminus, containing 22 amino acids, showed no homology to any known protein.

\section{Hs-Ubil is specifically expressed in the dorsal pharyngeal gland.}

Whole mount in situ hybridization on preparasitic J2 with the antisense probe of AFT88 gave a specific signal in the dorsal pharyngeal gland (Fig. 1). As the nucleotide sequence of AFT70 (Hs-Ubi2) and AFT88 were highly similar, no distinction could be made between the two genes. The expression of AFT88 during nematode development was analyzed by reverse transcriptase-polymerase chain reaction (RT-PCR) on manually dissected juveniles at different life stages (Fig. 2). An actin-specific probe was used as an internal positive control. A positive signal was obtained in all $\mathrm{J} 2$ stages, J3, and young adult females. The transcript was not detected in developing eggs and in adult males.

\section{Hs-UBI1 belongs to a novel class of ubiquitin extension proteins.}

During preparation of this manuscript, two genes highly homologous to the Hs-Ubil gene were identified in Heterodera glycines (Gao et al. 2003), and in addition, homologous expressed sequence tags (EST) have become available in the parasitic nematode database of the Genome Sequencing Center (McCarter et al. 2000) that are derived from H. glycines or Globodera rostochiensis, which also belong to the group of cyst nematodes. Both $H$. glycines genes and the translation

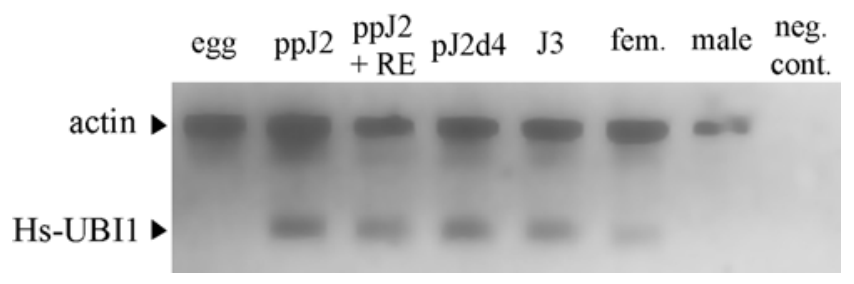

Fig. 2. Reverse transcriptase-polymerase chain reaction analysis of the expression of $H s-U B I 1$. Primers against actin were used as an internal control. $H s-U B I 1$ was expressed in preparasitic $\mathrm{J} 2(\mathrm{ppJ} 2)$, preparasitic J2 after soaking in root exudate (ppJ2 + RE), parasitic $\mathbf{J} 2$ four days after root inoculation ( $\mathrm{pJ} 2 \mathrm{~d} 4)$, third stage juveniles (J3), and young adult females (fem.). Transcript was absent in developing eggs (egg) and adult males (male); neg. cont.: no template. 
products of those EST containing the full-length open reading frame have the same overall structure as Hs-UBI1. A multiple alignment was performed with the Hs-UBI1 protein, the translation product of AFT70 (Hs-UBI2), both homologous $H$. glycines proteins, the translation products of two G. rostochiensis homologous EST, the monoubiquitin domain derived from polyubiquitin of Lycopersicon esculentum and Caenorhabditis elegans, and three types of the ubiquitin-like protein family (SUMO, UBQ-2, and NEDD8) in C. elegans (Fig. 3). Except for the SUMO protein, the ubiquitin domain was almost identical in all proteins. Besides Hs-UBI1 and the homologues, only UBQ-2 also has a C-terminal protein domain. However, the UBQ-2 C-terminal domain is much longer, and no significant amino acid homology was found between the C-termini of UBQ-2 and those of Hs-UBI1 and homologous proteins. Multiple alignment of Hs-UBI1 and the homologous proteins showed that several boxes of conserved amino acids are present in the signal peptide for secretion, while the C-terminal domains seem to vary considerably among the different cyst nematode species.

\section{Hs-UBI1 is secreted.}

To verify the secretion of the Hs-UBI1 protein, preparasitic J2 were labeled immunofluorescently with an antiubiquitin antibody. A very strong staining was observed in the dorsal pharyngeal gland extension, in which the secretions are col- lected before release in the pharyngeal lumen at the base of the stylet (Fig. 4A). Some other tissues, such as the genital primordia, were also stained, which was not surprising because ubiquitin itself is a common protein in all eukaryotic cells, fulfilling many different functions. However, we believe that the strong staining of the dorsal gland with the antiubiquitin antibody is due to the Hs-UBI1 protein, because in situ hybridization with only the gene-specific $3^{\prime}$ end of the $\mathrm{Hs}$-Ubil gene labeled exclusively and very strongly the dorsal gland. For ultrastructural investigation, preparasitic J2 were cryofixed and cryosubstituted, followed by embedding in LR White. Serial ultrathin sections were immunogold labeled with the antiubiquitin monoclonal antibody and were viewed with a transmission electron microscope. A clear gold label was found on the secretory granules present in the cell extension of the dorsal pharyngeal gland (Fig. 4B), indicating that the protein is indeed secreted.

\section{The C-terminal domain}

of Hs-UBI1 is translocated to the nucleolus in plant cells.

Considering that the Hs-UBI1 protein is injected via the nematode's stylet into the root cell, we analyzed the cellular sorting of the protein with the PSORT program. The secreted protein (ubiquitin and C-terminal domain) was predicted to be localized cytoplasmically, whereas the C-terminal polypeptide alone (with a $72 \%$ certainty) was predicted to be transported to
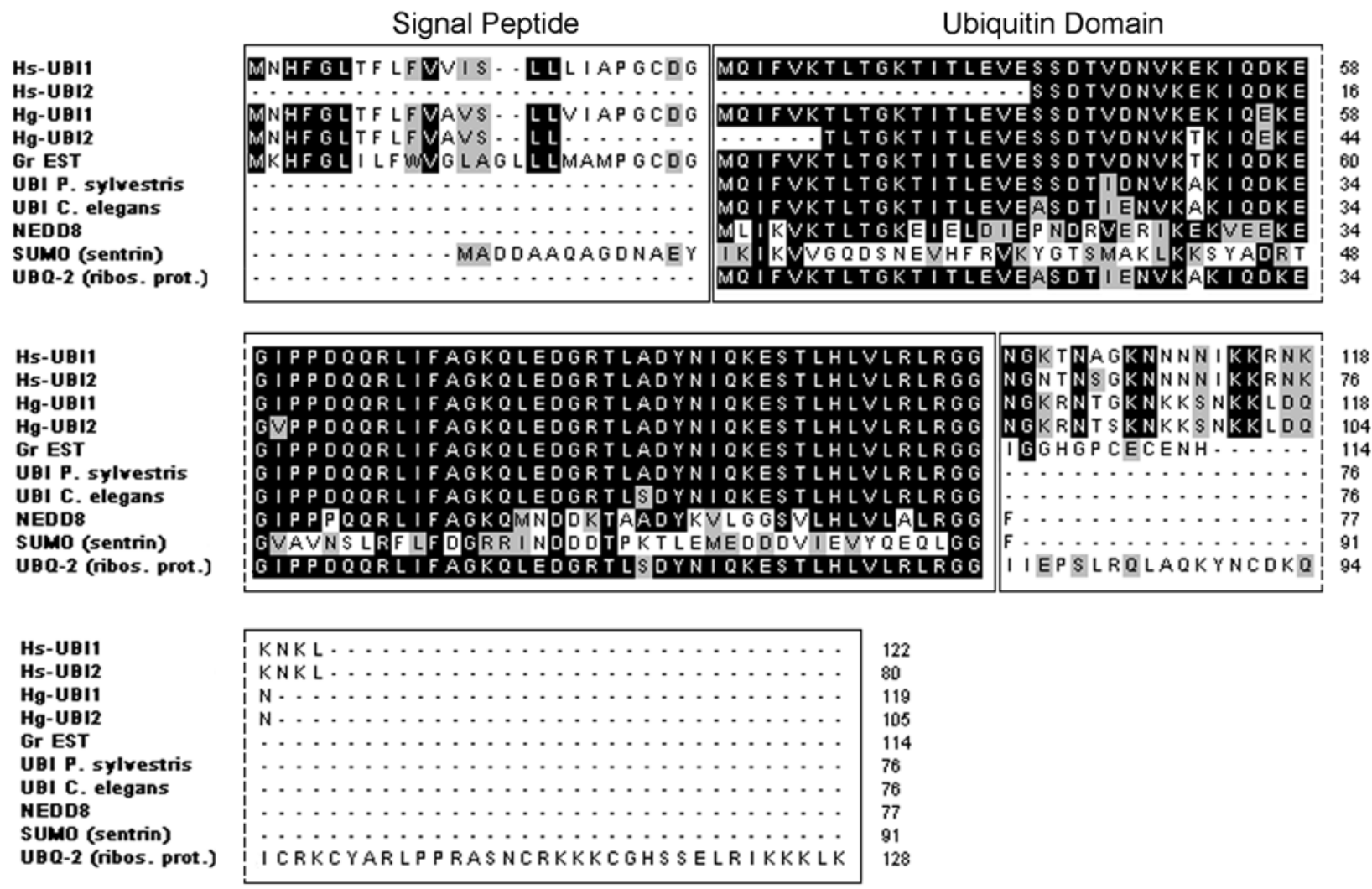

C-terminal Extension

Fig. 3. Multiple alignment of the Hs-UBI1 protein (accession number AY286305) with the translation product of the AFT70 transcript derived fragment (Hs-UBI2; accession number AY288520), two Heterodera glycines homologous genes (accession numbers AF469060 and AF473831), the translation products of a homologous expressed sequence tag of Globodera rostochiensis (accession number BM355031), the monoubiquitin domains of Caenorhabditis elegans (accession number P14792), the Pinus sylvestris polyubiquitin (accession number CAA66667), and the three types of ubiquitin-like family proteins of $C$. elegans: SUMO (Sentrin, accession number NP_490842), NEDD8 (accession number NP_492717), and UBQ-2 (ribosomal protein, accession number NP_499695). The three domains, signal peptide for secretion, monoubiquitin, and C-terminal extension domain are indicated. Although the homology between the C-terminal domains of Hs-UBI1 and UBQ-2 is very low, the overall structure of both proteins is similar. Comparison between Hs-UBI1 and its homologues in other cyst nematodes reveals that several boxes of conserved amino acids are present in the signal peptide for secretion, the ubiquitin domain is almost identical, but a large variation is present in the C-terminal extensions between different nematode species. In black, identical residues; in gray, conserved substitutions. 
the nucleus of the plant cell. Although the C-terminal domains of the ubiquitin extension proteins vary considerably among the different cyst nematode species, intracellular sorting analysis of the C-terminal domains in the Hs-UBI1 homologues of the other cyst nematodes gave similar nuclear localizations. To confirm this nuclear localization, a green fluorescent protein (GFP) fusion C-terminal of $\mathrm{Hs}$-Ubil without signal peptide for secretion was constructed and transformed into tobacco Bright Yellow-2 (BY-2) cells. The next day, a strong GFP illumination of the nucleolus was observed (Fig. 5).

\section{DISCUSSION}

To search for genes coding for pharyngeal gland secretions a cDNA AFLP analysis was performed on preparasitic and early parasitic stages of $H$. schachtii. Two differentially expressed TDF (AFT88 and AFT70) showed homology to polyubiquitin. In situ hybridization with the AFT88 antisense probe specifically stained the dorsal pharyngeal gland. After isolation and sequencing of the complete open reading frame, it was clear that we had found another protein than polyubiquitin. The protein contains three domains, of which one is a monoubiquitin. The first domain was predicted to be a signal peptide for secretion and, as such, would be cleaved off before injection into the plant cell. The third, C-terminal domain had no homology with any known protein. Secretion of the protein by the dorsal pharyngeal gland was confirmed by immunolocalization with an antiubiquitin antibody, which labeled the
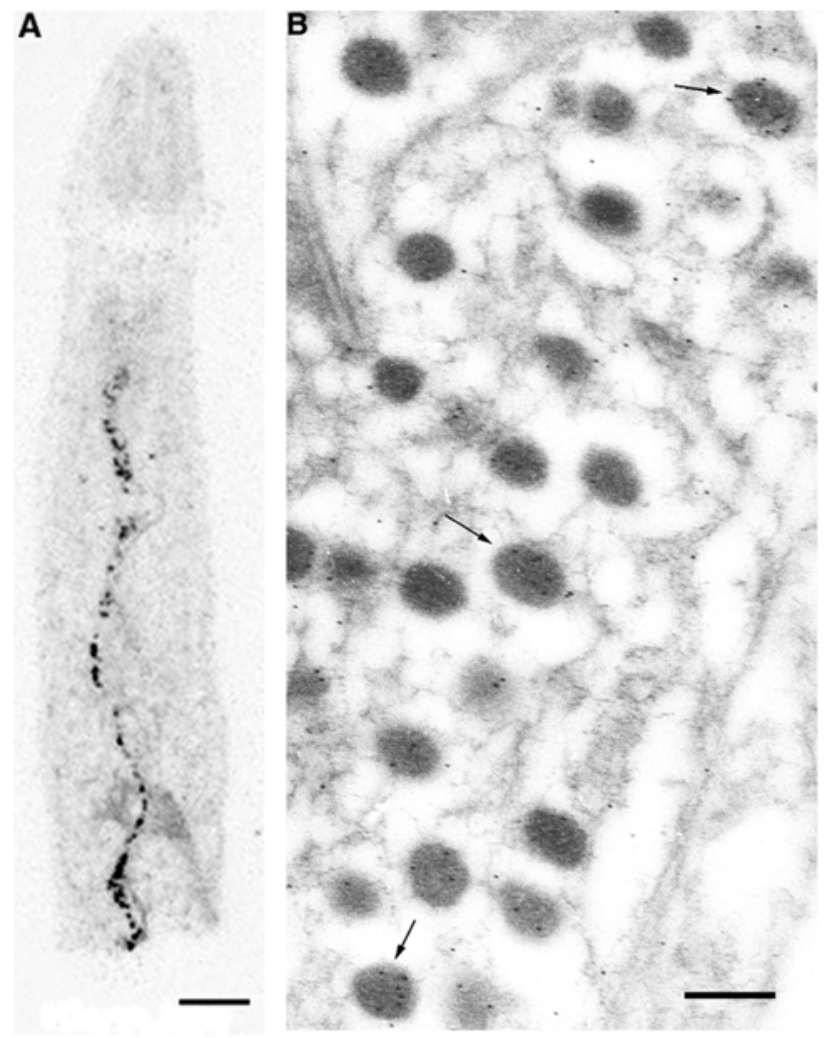

Fig. 4. Immunolocalization with an antiubiquitin antibody on preparasitic second stage juveniles of Heterodera schachtii. A, Whole-mount immunolocalization with a fluorescein isothiocyanate-labeled antiubiquitin antibody resulted in a very strong granular staining of the dorsal gland extension, in which secretions are collected before release in the pharyngeal lumen at the base of the stylet. Scale bar $=10 \mu \mathrm{m}$. B, Ultrastructural immunolocalization with a gold-labeled antiubiquitin antibody gave a clear gold label of the secretory granules (arrows) present in the dorsal gland extension. Scale bar $=250 \mathrm{~nm}$. secretory granules present in the gland. In other cyst nematodes, several other highly similar proteins were found.

Because of the high similarity of $\mathrm{Hs}$-Ubil and $\mathrm{Hs}$-Ubi2, no distinction between both genes could be made for the in situ hybridization, the RT-PCR as well as the immunolocalization. Probably, the signals obtained in these experiments are the sum of the signals resulting from both genes. We only isolated the $3^{\prime}$ end of the $H s$-Ubil gene, which contains a signal peptide for secretion. Therefore, we assume that at least Hs-UBI1 is secreted. According to the cDNA AFLP, both genes have a different expression pattern. However to confirm that, a more detailed quantitative RT-PCR with gene-specific primers should be done.

Ubiquitin is a protein of 76 amino acids found in all eukaryotic cells, whose sequence is very well conserved. It is a globular protein, the last four C-terminal residues (Leu-ArgGly-Gly) extending from the compact structure to form a tail important for its function. Ubiquitin is known to play crucial roles in a large variety of biological processes (Ciechanover 1994; Ciechanover and Schwartz 1994). In eukaryotes, there are many genes coding for ubiquitin (Hershko et al. 2000; Jentsch and Pyrowolakis 2000). They are classified into three groups, polyubiquitin, ubiquitin-like, and ubiquitin extension proteins. In the ubiquitin extension proteins, a ubiquitin monomer is fused to a C-terminal extension protein. The initial translation products of these genes are accurately and rapidly cleaved in vivo by ubiquitin C-terminal hydrolases (Wilkinson 1997). The extension proteins are constituents of mature ribosomes (Finley et al. 1989). The actual function of the monoubiquitin domain in these fusion proteins is still unclear, although it could act as a chaperone. Many ubiquitin extension proteins have been described with C-terminal domains of various lengths (Callis et al. 1990; Jones and Candido 1993). However, all C-terminal domains of these proteins are highly basic, contain a 4-cysteine residue sequence in consensus with

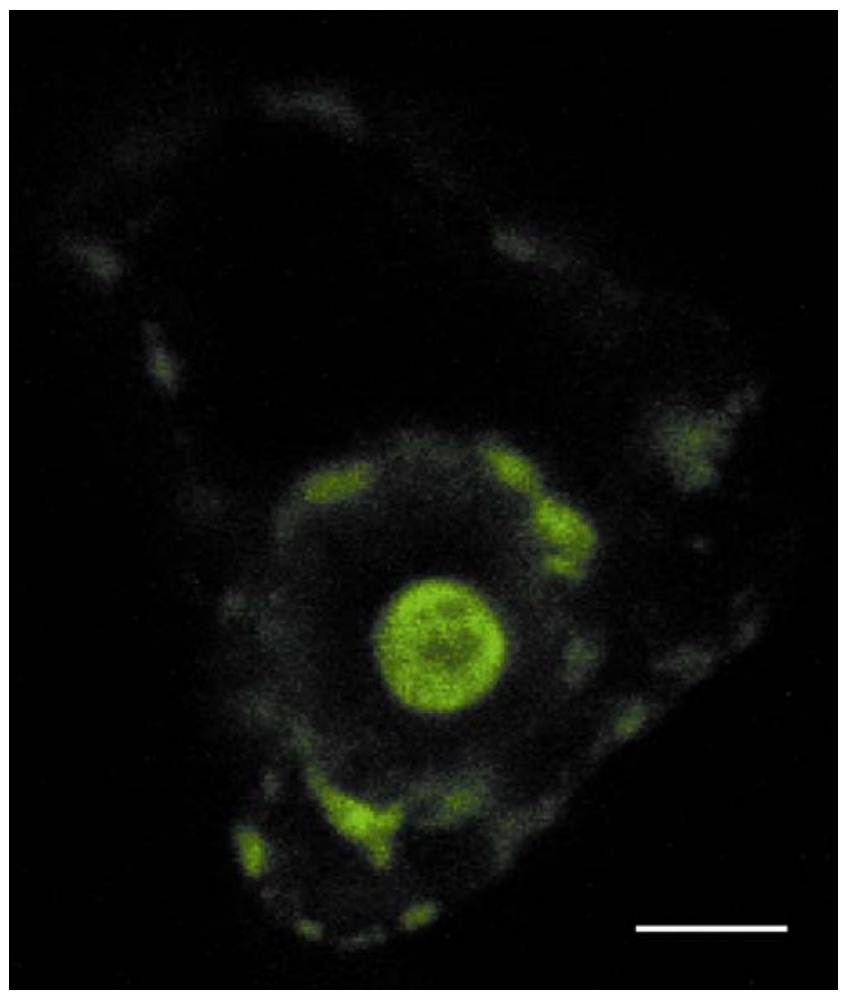

Fig. 5. Localization in tobacco BY-2 cells of a C-terminal green fluorescent protein (GFP) fusion of the Hs-UBI1 protein without the signal peptide for secretion. A strong GFP illumination of the nucleolus is observed. Scale bar $=10 \mu \mathrm{m}$. 
the zinc finger domain present in nucleic acid-binding proteins (Klug and Rhodes 1987), have a consensus sequence for nuclear localization (Kalderon et al. 1984), and show a high degree of homology among different species (Callis et al. 1990). The overall structure of Hs-UBI1 and its homologues mostly resembles the ubiquitin extension proteins, and the $\mathrm{C}$ terminal domain is also expected to be cleaved off. However, although the Hs-UBI1 C-terminal domain is highly basic, it lacks the 4-cysteine residues, indicating that, together with the homologues identified in other cyst nematodes, it forms a new class of ubiquitin extension proteins. The Hs-UBI1-GFP fusion was demonstrated to be targeted to the nucleolus.

In Magnaporthe grisea, a plant parasitic fungus, a ubiquitin extension protein is highly expressed during the initial stages of infection (McCafferty and Talbot 1998). Based on the expression of other genes, the authors conclude that, besides a role in ribosome biogenesis, this ubiquitin extension protein may also have another yet unidentified function. We can only speculate about the function of the new class of ubiquitin extension proteins in cyst nematodes. It is the first known ubiquitin extension protein that is secreted by one organism most likely to fulfill a role in another. As generally thought for the other ubiquitin extension proteins, probably only the C-terminal domain will have a function in the root cells. The nucleolar localization of the Hs-UBI1-GFP fusion points in the direction of ribosome synthesis, especially because the other ubiquitin extension proteins are known to be constituents of ribosomes. The function of the nucleolus as a factory for assembling ribosomal subunits is well established, but many unrelated activities have been discovered over the past decade (CarmoFonseca et al. 2000; Olson et al. 2000; Visintin and Amon 2000). Unexpectedly, the nucleolus also seems to play a role in nuclear transport, modifying small RNAs, assembling ribonucleoproteins, and controlling aging and cell cycle regulation. In plants, peptides are known to play a crucial role in growth and development, including the control of cell division and expansion (Lindsey et al. 2002). Recently, peptides smaller than $3 \mathrm{kDa}$ present in cyst nematode secretions have been shown to costimulate the proliferation of both tobacco leaf protoplasts and human peripheral mononuclear blood cells (Goverse et al. 1999). As cleavage of the ubiquitin extension proteins is performed by nuclear or cytoplasmic C-terminal hydrolases, we expect the cleavage of Hs-UBI1 to occur not in the nematode but only after injection into the feeding cell. Because $\mathrm{Hs}$-Ubil is specifically expressed in the dorsal pharyngeal gland, and because, during induction of the feeding site, release of dorsal gland secretions into the cytoplasm of the root cells was observed (Wyss 1992), we hypothesize that the short C-terminal domain plays a regulatory role in feeding cell formation. This hypothesis is supported by the presence of the $\mathrm{Hs}$ - Ubil transcript, analyzed by RT-PCR, during all parasitic life stages maintaining a feeding cell and the absence of it in adult males leaving the plant roots.

Although several aspects of the nematode-plant interaction are similar in root-knot and cyst nematodes (Davis et al. 2000) and threefold more EST are available for root-knot than for cyst nematodes, we found $12 \mathrm{Hs}$-Ubil homologous EST derived from cyst but none from root-knot nematodes, indicating that the short C-terminal polypeptide of Hs-UBI1 could play a role in syncytium development but not in giant cell formation.

\section{MATERIALS AND METHODS}

\section{CDNA AFLP.}

Heterodera schachtii was cultivated as described before (Tytgat et al. 2002). For each life stage, 20 J2 were cut mid- way. Prior to the microdissection, the $\mathrm{J} 2$ were partially dehydrated by incubation at room temperature for $1 \mathrm{~h}$ in a hypertonic buffer (Powers et al 1986) containing $168 \mathrm{mM}$ sucrose,

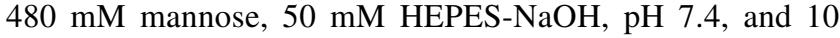
mM EDTA. Thereafter, they were transferred one by one to sterile water and quickly cut midway, whereby the anterior and posterior ends were put separately in an Eppendorf tube containing $50 \mu \mathrm{l}$ TRIzol reagent (Gibco-BRL Life Technologies Inc., Gaithersburg, MD, U.S.A.). The tubes were stored at $-70^{\circ} \mathrm{C}$ until further processing. Total RNA was isolated according to the manufacturer's instructions (Gibco-BRL Life Technologies Inc.), based largely on the method described by Chomczynski and Sacchi (1987). cDNA was synthesized with the SMART PCR cDNA synthesis kit (Clontech Laboratories, Palo Alto, CA, U.S.A.). To obtain sufficient material, the cDNA synthesis was immediately followed by an amplification reaction according to the manufacturer's instructions (Clontech Laboratories). After digestion of the cDNA (50 ng) with SacI and MseI, the cDNA AFLP procedure was as described (Bachem et al. 1996; Vos et al. 1995). Bands identified on the autoradiograph as differentially expressed were isolated out of the polyacrylamide gel, were reamplified, and were cloned in pGEMT (Promega Benelux, Leiden, The Netherlands) or were directly sequenced.

\section{Full-length cDNA isolation.}

To isolate the 5' end of the AFT88 cDNA, a nested PCR was performed with two gene-specific primers (5'-ACA CGG AAA CCA AAG AAA ACC-3' and 5'-TGT CTT CCC ATT TCC GCC-3') and an extended SP6 vector primer (5'-ATT TAG GTG ACA CTA TAG AAT ACT CAA GC-3') on a $H$. schachtii preparasitic J2 plasmid cDNA library. The first PCR was done in a $50-\mu \mathrm{l}$ reaction containing $1 \mu \mathrm{g}$ cDNA library DNA, $0.2 \mathrm{mM}$ dNTP, $0.2 \mu \mathrm{M}$ of sequence-specific primer, 0.2 $\mu \mathrm{M}$ vector primer, $5 \mu \mathrm{l} 10 \times$ PCR buffer (Perkin Elmer Corp., Norwalk, CT, U.S.A.), $1.5 \mathrm{mM} \mathrm{MgCl} 2$, and $2 \mathrm{U}$ Taq polymerase (Perkin Elmer Corp.). In the second PCR, $2 \mu \mathrm{l}$ of a 1:100 dilution of the first PCR was used as a template. Cycling conditions were: $94^{\circ} \mathrm{C}$ for $2 \mathrm{~min}$, followed by 30 cycles of $94^{\circ} \mathrm{C}$ for $30 \mathrm{~s}, 60^{\circ} \mathrm{C}$ for $30 \mathrm{~s}$, and $72^{\circ} \mathrm{C}$ for $3 \mathrm{~min}$. From both PCR reactions, a sample was checked by agarose gel electrophoresis. The amplification product was cloned in pGEMT, and three separate clones were sequenced.

\section{Bioinformatics.}

Sequence homology searches were done with the different BLAST programs available at the National Center for Biotechnology Informatics website or on the parasitic nematode database of the Genome Sequencing Center (McCarter et al. 2000). Signal peptide for secretion analysis was with the SignalP V2.0 program (Nielsen et al. 1999), available on the Center for Biological Sequence Analysis website. Intracellular sorting of proteins was predicted with PSORT or the ProtCom program. Multiple sequence alignments were done using the ClustalW Tool available in the BioEdit program.

\section{In situ hybridization.}

Whole-mount in situ hybridization of freshly hatched $H$. schachtii second stage juveniles was performed with digoxigenin-labeled single-strand DNA probes as described before (Vanholme et al. 2002).

\section{RT-PCR.}

Individuals (10 to 40) from seven different life stages were collected. Those stages were developing eggs, preparasitic $\mathrm{J} 2$, preparasitic $\mathrm{J} 2$ soaked in root exudates, parasitic $\mathrm{J} 2$ four 
days after inoculation, J3, young adult females, and adult males. Total RNA was isolated using Trizol, and cDNA was synthesized with the super-SMART PCR synthesis kit (Clontech Laboratories). To obtain sufficient material, the cDNA synthesis was immediately followed by an amplification reaction according to the manufacturer's instruction. Amplified cDNA $(1 \mu \mathrm{l}), 1 \mu \mathrm{l}$ of $10 \mathrm{mM}$ dNTP mix, $1 \mu \mathrm{l}$ of $10 \mu \mathrm{M}$ UBFLRN (5'-AGA AAG CTG GGT TTC AGA GCT TGT TCT TCT TGT TTC TCT TCT TGA TG), and $1 \mu \mathrm{l} 10 \mu \mathrm{M}$ UBFRFC2 (5'-AAA AAG CAG GCT TCA CCA TGG GCG GAA ATG GGA AGA CAA ACG CGG GTA AG), $5 \mu \mathrm{l} 10 \times$ PCR buffer, and $1 \mathrm{U} T a q$ polymerase were used in a $50-\mu \mathrm{l}$ PCR reaction. Two additional primers (Hs-actF: 5'-ACT TCA

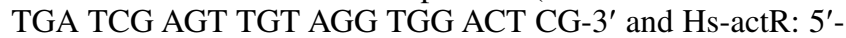
GAC CTC ACT GAC TAC CGA TGA AGA TTC-3') designed to amplify actin were used as an internal control of the PCR reaction. PCR conditions were as follows: $94^{\circ} \mathrm{C}$ for $1 \mathrm{~min}$, followed by 24 cycles at $94^{\circ} \mathrm{C}$ for $15 \mathrm{~s}, 60^{\circ} \mathrm{C}$ for $25 \mathrm{~s}$, and $72^{\circ} \mathrm{C}$ for $45 \mathrm{~s}$. As a negative control, water was used instead of template. PCR products were run on a $1.5 \%$ agarose gel.

\section{Whole-mount immunolocalization.}

Hatched second stage juveniles were fixed in $3 \%$ paraformaldehyde for 30 min under vacuum at room temperature and for another $20 \mathrm{~h}$ at $4^{\circ} \mathrm{C}$. All other steps were performed as described (Goverse et al. 1994), with minor modifications. The primary rabbit antiubiquitin antibody (Sigma-Aldrich, St Louis) was visualized using a fluorescein isothiocyanate-conjugated secondary antibody. The nematode sections were analyzed with a Radiance 2000 confocal microscope (Bio-Rad Laboratories, Hercules, CA, U.S.A.).

\section{Ultrastructural immunolocalization.}

Freshly hatched $\mathrm{J} 2$ were transferred to distilled water and high pressure-frozen in liquid nitrogen in a Leica EMPact cryofixation device (Leica, Vienna, Austria). Only specimens that were cryofixed at pressures of 2,000 bar in less than 5 ms were processed further. Cryosubstitution was carried out using a Leica AFS (Leica). The cryosubstitution process consisted of a substitution phase in methanol at $-85^{\circ} \mathrm{C}$ for $76 \mathrm{~h}$ and a warming phase. The warming phase started with a slope of $3^{\circ} \mathrm{C} / \mathrm{h}$ until $-30^{\circ} \mathrm{C}$, a plateau for $8 \mathrm{~h}$, and again, a slope of $3{ }^{\circ} \mathrm{C} / \mathrm{h}$ until $4^{\circ} \mathrm{C}$. Thereafter, specimens were embedded in LR White (London Resin Company Ltd., Berkshire, England) at $4{ }^{\circ} \mathrm{C}$ by gradually increasing the concentration of LR White during a period of $48 \mathrm{~h}$ until it reached $100 \%$, followed by an overnight polymerization under UV. The 70-nmthick serial sections were cut using a Leica Ultracut S (Leica) and were collected on Gilder single-slot grids (Laborimpex, Brussel, Belgium).

Immunogold labeling with a 1:25 diluted rabbit antiubiquitin antibody (Sigma) was performed as described elsewhere (Espeel and Van Limbergen 1995). Counterstaining and visualization of the sections was as described before (Tytgat et al. 2002).

\section{Localization in tobacco BY-2 cells.}

Using a PCR-based approach, a fragment of $\mathrm{Hs}$-Ubil was isolated from the cDNA library. This fragment, depleting the predicted signal peptide, was cloned in the pK7FWG2 vector (Karimi et al. 2002) with the Gateway Cloning facilities (Invitrogen, Carlsbad, CA, U.S.A.). The obtained vector was delivered to BY-2 cells with a Biolistic PDS-1000/He particle delivery system (vacuum, 26 inches $\mathrm{Hg}$; helium pressure, 1,100psi; gold particles, $1 \mu \mathrm{m})$ (Bio-Rad). After transformation $(16 \mathrm{~h})$, the cells were analyzed with a Radiance 2000 (Bio-Rad) confocal microscope.

\section{ACKNOWLEDGMENTS}

We thank M. De Cock for critical reading of the manuscript. This research was supported by the Fund for Scientific Research-Flanders (G.0078.97) and the European Union (NONEMA EC, QLT-CT-1999-01501). B. Vanholme is indebted to the Lamas Instituut voor de bevordering van het WetenschappelijkTechnologisch Onderzoek in de Industrie for a predoctoral fellowship.

\section{LITERATURE CITATIONS}

Bachem, C. W. B., Van Der Hoeven, R. S., De Bruijn, S. M., Vreugdenhil, D., Zabeau, M., and Visser, R. G. F. 1996. Visualisation of differential gene expression using a novel method of RNA fingerprinting based on AFLP: Analysis of gene expression during potato tuber development. Plant J. 9:745-753.

Callis, J., Raasch, J. A., and Vierstra, R. D. 1990. Ubiquitin extension proteins of Arabidopsis thaliana. J. Biol. Chem. 265:12486-12493.

Carmo-Fonseca, M., Mendes-Soares, L., and Campos, I. 2000. To be or not to be in the nucleolus. Nature Cell Biol. 2:E107-E112.

Chomczynski, P., and Sacchi, N. 1987. Single-step method of RNA isolation by acid guanidinium thiocyanate-phenol-chloroform extraction. Anal. Biochem. 162:156-159.

Ciechanover, A. 1994. The ubiquitin-mediated proteolytic pathwayMechanisms of action and cellular physiology. Biol. Chem. H.-S. 375:565-581.

Ciechanover, A., and Schwartz, A. L. 1994. The ubiquitin-mediated proteolytic pathway-Mechanisms of recognition of the proteolytic substrate and involvement in the degradation of native cellular proteins. FASEB (Fed. Am. Soc. Exp. Biol.) J. 8:182-191.

Davis, E. L., Allen, R., and Hussey, R. S. 1994. Developmental expression of esophageal gland antigens and their detection in stylet secretions of Meloidogyne incognita. Fund. Appl. Nematol. 17:255-262.

Davis, E. L., Hussey, R. S., Baum, T. J., Bakker, J., and Schots, A. 2000. Nematode parasitism genes. Annu. Rev. Phytopathol. 38:365-396.

De Meutter, J., Vanholme, B., Bauw, G., Tytgat, T., Gheysen, G. D. C. and Gheysen, G. D. R. 2001. Preparation and sequencing of secreted proteins from the pharyngeal glands of the plant parasitic nematode Heterodera schachtii. Mol. Plant Pathol. 2:297-301.

Espeel, M., and Van Limbergen G. 1995. Immunocytochemical localization of peroxisomal proteins in human liver and kidney. J. Inherit. Metab. Dis. 18 Suppl. 1:135-154.

Fenoll, C., Grundler, F. M. W., and Ohl, S. A. 1997. Cellular and Molecular Aspects of Plant-Nematode Interactions. Kluwer Academic Publishers, Dordrecht, The Netherlands.

Finley, D., Bartel, B., and Varshavsky, A. 1989. The tails of ubiquitin precursors are ribosomal-proteins whose fusion to ubiquitin facilitates ribosome biogenesis. Nature 338:394-401.

Gao, B., Allen, R., Maier, T., Davis, E. L., Baum, T. J., and Hussey, R. S. 2003. The parasitome of the phytonematode Heterodera glycines. Mol. Plant-Microbe Interact. 16:720-726.

Gheysen, G., and Fenoll, C. 2002. Gene expression in nematode feeding sites. Annu. Rev. Phytopathol. 40:191-219.

Goverse, A., Davis, E. L., and Hussey, R. S. 1994. Monoclonal antibodies to the esophageal glands and stylet secretions of Heterodera glycines. J. Nematol. 26:251-259.

Goverse, A., Van Der Voort, J. R., Van Der Voort, C. R., Kavelaars, A., Smant, G., Schots, A., Bakker, J., and Helder, J. 1999. Naturallyinduced secretions of the potato cyst nematode co-stimulate the proliferation of both tobacco leaf protoplasts and human peripheral mononuclear blood cells. Mol. Plant-Microbe Interact. 12:872-881.

Hershko, A., Ciechanover, A., and Varshavsky, A. 2000. The ubiquitin system. Nat. Med. 6:1073-1081.

Jentsch, S., and Pyrowolakis, G. 2000. Ubiquitin and its kin: How close are the family ties? Trends Cell Biol. 10:335-342.

Jones, D., and Candido, E. P. M. 1993. Novel ubiquitin-like ribosomal protein fusion genes from the nematodes Caenorhabditis elegans and Caenorhabditis brigssae. J. Biol. Chem. 268:19545-19551.

Kalderon, D., Roberts, B. L., Richardson, W. D., and Smith, A. E. 1984. A short amino-acid sequence able to specify nuclear location. Cell 39:499-509.

Karimi, M., Inzé, D., and Depicker, A. 2002. GATEWAY ((TM)) vectors for Agrobacterium-mediated plant transformation. Trends Plant Sci. 7:193-195.

Klug, A., and Rhodes, D. 1987. Zinc fingers-A novel protein motif for nucleic-acid recognition. Trends Biochem. Sci. 12:464-469.

Lindsey, K., Casson, S., and Chilley, P. 2002. Peptides: New signaling molecules in plants. Trends Plant Sci. 7:78-83.

McCafferty, H. K. M., and Talbot, N. J. 1998. Identification of three ubiquitin extension genes of the rice blast fungus Magnaporthe grisea, one 
of which is highly expressed during initial stages of plant colonisation. Curr. Genet. 33:352-361.

McCarter, J., Abad, P., Jones, J. T., and Bird, D. 2000. Rapid gene discovery in plant parasitic nematodes via expressed sequence tags. Nematology 2:719-731.

Nielsen, H., Brunak, S., and von Heijne, G. 1999. Machine learning approaches to prediction of signal peptides and other sorting signals. Prot. Eng. 12:3-9.

Olson, M. J. O., Dundr, M., and Szebeni, A. 2000. The nucleolus an old factory with unexpected capabilities. Trends Cell Biol. 10:189-196.

Powers, T. O., Platzer, E. G., and Hyman, B. C. 1986. Species-specific restriction site polymorphism in root-knot nematode mitochondrial DNA. J. Nematol. 18:288-293.

Smant, G., Stokkermans, J. P. W. G., Yan, Y., De Boer, J. M., Baum, T. J., Wang, X., Hussey, R. S., Gommers, F. J., Henrissat, B., Davis, E. L., Helder, H., Schots, A., and Bakker, J. 1998. Endogenous cellulases in animals: Isolation of $\beta$-1,4-endoglucanase genes from two species of plant-parasitic cyst nematodes. Proc. Natl. Acad. Sci. U.S.A. 95:4906-4911.

Tytgat, T., De Meutter, J., Gheysen, G., and Coomans, A. 2000. Sedentary endoparasitic nematodes as a model for other plant parasitic nematodes. Nematology 2:113-121.

Tytgat, T., De Meutter, J., Vanholme, B., Claeys, M., Verreijdt, L., Gheysen, G., and Coomans, A. 2002. Development and pharyngeal gland activities of Heterodera schachtii infecting Arabidopsis thaliana roots. Nematology 4:899-908.

Vanholme, B., De Meutter, J., Tytgat, T., Gheysen, G. D. C., Vanhoutte, I., and Gheysen, G. D. R. 2002. An improved method for whole mount in situ hybridization of Heterodera schachtii juveniles. Parasitol. Res. 88:731-733.
Visintin, R., and Amon, A. 2000. The nucleolus: The magician's hat for cell cycle control. Curr. Opin. Cell Biol. 12:372-377.

Vos, P., Hogers, R., Bleeker, M., Reijans, M., Hornes, M., Frijters, A., Pot, J., Peleman, J., Kuiper, M., Zabeau, M., and Van De Lee, T. 1995. AFLP: A new technique for DNA fingerprinting. Nucleic Acids Res. 23:4407-4414.

Wilkinson, K. 1997. Regulation of ubiquitin-dependent processes by deubiquitinating enzymes. FASEB (Fed. Am. Soc. Exp. Biol.) J. $11: 1245-1256$

Wyss, U. 1992. Observations on the feeding behaviour of Heterodera schachtii throughout development, including events during molting. Fund. Appl. Nematol. 15:75-89.

Wyss, U., and Zunke, U. 1986. Observations on the behaviour of second stage juveniles of Heterodera schachtii inside host roots. Rev. Nematol. 9:153-165.

\section{AUTHOR-RECOMMENDED INTERNET RESOURCES}

BioEdit, a biological sequence alignment editor program for Windows 95/98/NT/2000/XP: www.mbio.ncsu.edu/BioEdit/bioedit.html

Center for Biological Sequence Analysis SignalP World Wide Web server: www.cbs.dtu.dk/services/SignalP

National Center for Biotechnology Informatics BLAST website: www3.ncbi.nlm.nih.gov/BLAST

PSORT: psort.nibb.ac.jp

Softberry Inc. ProtCom program: www.softberry.com/berry.phtml

Washington University School of Medicine Genome Sequencing Center: www.nematode.net 